GEOUSP - Espaço e Tempo, São Paulo, No 28, pp. 34 - 58, 2010

\title{
PROPOSIÇÕES PARA A ANÁLISE DA DIFERENCIAÇÃO ESPACIAL NOS ESTUDOS SOBRE REDE URBANA: AS NOÇÕES DE CONVERGÊNCIA E DIVERGÊNCIA ${ }^{1}$
}

\author{
Kelly Bessa*
}

\section{RESUMO:}

Os estudos urbanos vêm de longa data apontando para os processos de diferenciação entre os centros e suas respectivas redes urbanas, definidos pela complexidade genética e pela complexidade das estruturas dimensionais, funcionais e espaciais. Tais processos, contudo, apresentam especificidades, dentre as quais se destaca a re-diferenciação entre centros que estão no comando de dado segmento de rede. Na realidade, trata-se da ascensão de um novo centro, sob bases novas e mais amplas, em detrimento de um antigo, indicando mudanças com descontinuidade, caracterizadas, sobretudo, por processos de convergência e divergência, ou seja, pela contradição entre ações igualizadoras e ações diferenciadoras, que resultam em reestruturação da rede urbana.

Palavras-chave: rede urbana, espaço, diferenciação espacial, convergência, divergência.

\section{ABSTRACT:}

The urban studies has come a long ago pointing to the differentiation process between the centre and its respective urban networks, defined by the complexity genetic and by the complexity of dimensional, functional and spatial structures. Such processes, though, shoes specificities, among its highlights redifferentiation between the centre that are leading of such web segment. In reality, it deals about the rising of a new centre, beneath new and bigger bases, in detriment of an antique, indicating changes with discontinuity, character, although, by processes of convergence and divergence, it means, by the contradiction between same actions and differentiable actions, that results in a restructuring of the urban network.

Key words: urban network, space, spatial differentiation, convergence, divergence.

\section{Introdução}

Na tradição geográfica, uma das vias principais de abordagem acerca da temática da rede urbana diz respeito à diferenciação de seus centros, que, a despeito de funcionalmente articulados, apresentam-se cada vez mais distintos uns dos outros. Nas palavras de Corrêa (2000, p. 121), há uma "...diversidade dos inúmeros conjuntos articulados de centros urbanos", isto é, existe uma multiplicidade de redes urbanas, cada uma apresentando importante "...diferenciação entre suas cidades", como igualmente assinala Corrêa (1988, p. 119).

Há, entre os centros, maior ou menor distinção, até mesmo considerando-se o conjunto de centros de uma mesma rede urbana, quer dizer, aglomerações urbanas oriundas de um mesmo processo de criação, que não foram a priori diferenciadas por uma complexidade genética, podem mostrar-se profundamente diferenciadas entre si, pois, na maioria das vezes, respondem por processos distintos de evolução urbana. Muitos permanecem fortemente ligados à sua herança

*Profa. Dra. da Universidade Federal do Tocantins 
Proposições para a análise da diferenciação espacial nos estudos sobre

sobre rede urbana: as noções de convêrgencia e divergência, pp. 34 - 58

histórica, outros mostram alguma variação, principalmente em decorrência do papel diferencial que passam a desempenhar na rede, enquanto outros variam por completo, expressando a descontinuidade das mudanças, que podem ser radicais. Mesmo em níveis considerados paralelos ou em categorias tidas como homólogas, os centros urbanos apresentam extrema diferenciação. Exemplo notório são os pequenos centros, cuja distinção ocorre pela "...criação de novos centros... em áreas que passam a integrar - espaço globalizado" e também pelas "... alterações funcionais ou refuncionalização dos pequenos centros preexistentes", que ampliam as possibilidades de interações espaciais, como ensina Corrêa (1999, p. 47). Assim como no que se refere aos centros regionais que mudaram de conteúdo e de qualidade, à medida que se transformaram em espaços da produção agrícola, industrial e de expansão das atividades terciárias. Até mesmo entre as metrópoles existem diferenças significativas. As metrópoles regionais, do mesmo modo, revelam uma grande diversidade, pois, como observa Corrêa (2004), diferenciam-se segundo a gênese, a evolução urbana, o tamanho, o papel urbano que desempenham e quanto aos seus arranjos espaciais, sejam nas hinterlândias que comandam, sejam nas interações de longa distancia, caracterizando uma crescente dissociação entre proximidade espacial e o desempenho das funções básicas e não-básicas.

Contudo os processos de diferenciação dos centros na rede urbana apresentam especificidades. Dentre essas, destacam-se os processos de re-diferenciação entre centros que estão no comando e sustentam o fato urbano num dado escalão da rede, que, em suma, expressam a transferência de controle de um centro em declínio para um outro emergente, implicando profunda distinção entre eles. Vejam-se os processos de distinção entre São Paulo e Rio de Janeiro, nos quais se percebe a decadência da metrópole carioca em favor da ascensão da metrópole paulista, que "...se torna a inconteste metrópole nacional, o principal centro de gestão do território", como salienta Corrêa (2004, p. 7273). À primeira vista, essa situação que resulta em re-hierarquização e consequente reatualização do padrão espacial da rede urbana brasileira pode parecer atípica, pouco comum, tendo em vista os intensos processos de permanência que tendem a privilegiar os principais centros urbanos. Porém outros precedentes podem ser mencionados, uma vez que mesmo em escala internacional e em temporalidades distintas ocorreram essas diferenciações peculiares, indicando a possibilidade de estudos sincrônicos e diacrônicos. Braudel, citado por Arrighi (1996, p. 15), aponta que mudanças sucessivas alteraram os centros de comando mundial, posto que "...Amsterdã copiou Veneza, tal como Londres viria posteriormente a copiar Amsterdã e como Nova York, um dia, copiaria Londres". Em escala regional também se observa tais processos de alteração na hierarquia urbana, como o exemplo de Palmeira dos Índios e de Arapiraca, situados no Agreste e Sertão de Alagoas, onde "...uma nova área, Arapiraca, passa a comandar e a centralizar as atividades urbanas anteriormente existentes em Palmeira dos Índios", como sugere Ferrari (1988, p. 29). Do mesmo modo, os processos de rediferenciação e re-hierarquização entre Uberaba e Uberlândia, no Triângulo Mineiro, como registrado por Bessa (2007). Trata-se, em realidade, da ascensão de um novo centro, sob bases novas e mais amplas, em função do declínio de um antigo, expressando mudanças com descontinuidade, que resultam em reorganização e reestruturação da rede urbana.

A investigação que se segue objetiva elucidar como ocorrem os processos de diferenciação na rede urbana e em que condições eles podem acontecer, no intuito de tornar inteligíveis a lógica e a natureza desses processos, nos quais se destacam os de re-diferenciação. No caso específico de re-diferenciação entre centros que estão no comando de dado segmento da rede, ressalta-se que tal contexto é, primordialmente, orientado por processos de convergência e divergência. De fato, há uma justaposição de processos que, orientados ora por efeitos igualizadores ora por efeitos diferenciadores, resultam em re-diferenciação e consequente reatualização da rede. Nessa perspectiva, a diferenciação espacial, proveniente da contradição 
entre processos de convergência e divergência, coloca no cerne do debate o espaço e seu complexo movimento de reestruturação. Assim, alguns questionamentos colocam-se como vitais: como e quando ocorrem os processos de diferenciação pura e simples, bem como os processos de re-diferenciação, entre centros de um mesmo segmento da rede urbana? Quais agentes estão diretamente envolvidos na reorganização do padrão espacial da rede urbana? Qual a natureza desses processos?

\section{1 - A dinâmica da diferenciação na rede urbana}

A diferenciação entre os centros urbanos e suas respectivas redes, como refere Corrêa (2000), é perceptível por meio das múltiplas possibilidades de combinação e recombinação entre elementos próprios à natureza desse tipo de rede, que, inclusive, são determinantes basilares de sua estrutura e funcionamento. Dentre outros, destacam-se, primordialmente, gênese, posição relativa, tamanho e funções dos centros urbanos, assim como natureza, intensidade e alcance das interações espaciais mantidas por eles, juntamente com o próprio padrão espacial da rede. A combinação singular desses elementos, em um espaço-tempo, determina a estrutura espacial de uma rede urbana específica e constitui dado essencial de distinção, sendo que a eles somamse também outros aspectos de caráter econômico, político e sociocultural, cujas racionalidades interferem, de maneira decisiva, no ordenamento dos elementos primeiramente mencionados. Em realidade, o padrão espacial das redes urbanas é expressão e condição daquilo que o organiza, quer dizer, das lógicas e princípios que determinam uma dada ordem espacial dos seus elementos constitutivos, que, simultaneamente, tornam-se instrumentos de análise, possibilitando ultrapassar os limites da mera descrição e, assim, buscar uma reflexão mais ampla sobre o padrão espacial da rede, bem como sobre aquilo que preside sua natureza.

As múltiplas combinações entre os elementos acima indicados, que expressam a diversidade das redes urbanas, como observa Corrêa (2000, p. 122), "...evidenciam diferenças que, em realidade, pressupõem determinações mais profundas e complexas", ou seja, explicitam diferenças que, em suma, "...são expressões e condições... de estruturas sócio-espaciais mais profundas, historicamente produzidas". De fato, a combinação desses elementos tem uma lógica, uma coerência, pois a rede urbana "...está submetida a um dinamismo, maior ou menor e com ritmos variados, próprio a cada contexto espaço-temporal", como sugere Corrêa (2001, p. 424). Efetivamente, a rede urbana insere-se como parte constitutiva de um contexto socioespacial, sendo, por conseguinte, compatível com a própria estrutura social, que, por sua vez, é definidora de dadas formas e de determinados processos espaciais. Nas palavras de Castells (1999, p. 435), "...as formas e processos espaciais são constituídos pela dinâmica de toda a estrutura social". Dessa maneira, a estrutura social desempenha, como afirma Corrêa (2000, p. 122), papel relevante "...na inteligibilidade de uma dada rede urbana por meio do desvendamento das lógicas que geraram e articulam seus já mencionados elementos".

Portanto, para entender a rede urbana, cumpre apreender a coerência, a lógica da estrutura socioespacial, que desempenha importante papel no sentido de tornar compreensíveis as lógicas geratrizes que, na fase embrionária de uma dada rede urbana, impuseram um padrão específico de combinação de seus elementos peculiares, atribuindo a ela uma identidade singular. No mesmo sentido, cabe entender as lógicas dinamizadoras que desarticulam a combinação pretérita e rearticulam uma nova configuração espacial para essa rede, definida por essa ou por aquela recombinação de elementos que se manifestam de modo integrado num dado contexto espaço-temporal, resultando num padrão de rede diferente do anterior, pois sua estrutura e seu funcionamento foram transformados. De modo prático-sensível, é dessa forma que a rede urbana se transforma e, consequentemente, se diferencia.

Não importa, contudo, considerar apenas a recombinação dos elementos em si, mas 
Proposições para a análise da diferenciação espacial nos estudos sobre

sobre rede urbana: as noções de convêrgencia e divergência, pp. 34 - 58

os princípios que presidem o novo ordenamento, ou seja, as lógicas que qualificam essa nova combinação. Desse modo, sumaria-se que o desvendamento das lógicas geratrizes e das lógicas dinamizadoras pressupõe determinações complexas associadas à própria estrutura social e à sua dinâmica, pois a realidade está sempre em movimento, uma vez que a mudança é um aspecto essencial à existência e reprodução social. Tais determinações conferem à rede urbana e à seus centros uma configuração espacial associada a cada contexto espaço-temporal, sobreposta aos contextos antecedentes, presumindo composições singulares, cuja temporalidade, como assegura Corrêa (2000, p.122), representa "...determinante fundamental que fixa, ao menos temporariamente, os elementos combinados da rede urbana". Assim, a análise diacrônica expõe os momentos de relativa estabilidade, quando se cristaliza, pelos menos durante certo tempo, um determinado padrão, assim como revela o caráter mutável da rede urbana, tanto funcional como espacialmente, visto que, no processo evolutivo da formação socioespacial, uma rede simples, quem sabe do tipo dendrítico, pode se transformar numa rede mais complexa, talvez próxima de um padrão do tipo christalleriano, ou, até mesmo, numa rede bastante complexa, a exemplo das redes de múltiplos circuitos ${ }^{2}$. Nessa perspectiva, as análises diacrônicas, além de revelarem a dimensão dos processos gerais que engendram a situação geográfica no todo e na diversidade de suas expressões particulares, mostram os momentos de ruptura com a estabilidade e, consequentemente, os movimentos de mudança da rede urbana, revelando o seu caráter variante ${ }^{3}$.

A dinâmica de atualização da rede urbana está, assim, associada às racionalidades que ativam a passagem de um padrão particular de combinação dos elementos que definem uma dada configuração para um outro padrão igualmente particular, o que, muitas vezes, resulta em processos de diferenciação pura e simples, bem como em processos de re-diferenciação, cujas implicações são mais complexas, uma vez que a posição geográfica é alterada pelo declínio imediato ou gradativo de determinados centros em favor da ascensão de outros, sobretudo pelo surgimento de novas e importantes aglomerações urbanas próximo a centros historicamente tradicionais. Dessa maneira, inquietações se estabelecem como questões para a reflexão: que racionalidades interferem nos elementos combinados da rede urbana, encarregando-se de mudar esses elementos e suas respectivas combinações, no sentido de possibilitar a passagem de um dado padrão espacial para outro, cujo resultado é o movimento de transformação da própria rede? Tais racionalidades estão relacionadas com os momentos de ruptura social, expressos, geralmente, por transformações organizacionais ou tecnológicas? Qual o papel dos atores econômicos, políticos e sociais na recombinação dos elementos essenciais à rede urbana? São racionalidades de natureza convergente ou divergente?

2 - As especificidades da diferenciação entre os centros urbanos

A rede urbana, como assevera Corrêa (1988), desempenha papéis diretamente associados a dois amplos circuitos de exploração dos centros de acumulação de capital e poder sobre a região. Tais circuitos encontram-se profundamente imbricados entre si, pois, de um lado, baseiam-se na complexidade do processo de emigração campo-cidade, de comercialização da produção rural e drenagem da renda fundiária, e, de outro, na complexidade do processo de investimentos de capitais, de consumo de bens e serviços, e de difusão de valores e ideias, que sintetizam o intricado sistema financiamentoprodução-beneficiamento-comercializaçãodistribuição-consumo de produtos e também de ideários. Ressalta-se que ambos contribuem, de maneira significativa, com os processos de diferenciação entre os centros urbanos.

No primeiro circuito, os centros de acumulação de capital e poder extraem excedentes do campo, especialmente via beneficiamento/processamento e distribuição/ comercialização da produção agropecuária e extrativista, no qual se cria "...uma cadeia urbana de beneficiamento e comercialização da produção rural", que, por sua vez, se torna "...uma cadeia urbana de exploração de lucros comerciais" 
(CORRÊA, 1988, p.115-116), quer dizer, de lucros mercantis, que incorporam produtores, fornecedores, industriais, distribuidores, dentre outros agentes. Tal circuito perpassa também pela drenagem da renda fundiária, posto que "...parcela ponderável do valor excedente produzido no campo é transferida para as cidades", ampliando a acumulação de capital no urbano (CORRÊA, 1989, p.61); e, ainda, pelo processo de emigração campo-cidade, no qual a população migra do campo e cidades pequenas para as médias e grandes cidades.

No segundo circuito, tais centros de acumulação distribuem, para os centros subordinados ao longo da rede e para o campo, capitais, bens e serviços, valores e ideias, num claro processo de difusão, que incorpora o comércio atacadista e varejista, dentre outros intermediadores. Tal processo perpassa, notadamente, pelo investimento de capitais de grandes empresas em sucessivas aglomerações urbanas, que assumem maior importância como localidades centrais, e também no campo; bem como pelo consumo e demandas do campo e dos centros subordinados, geralmente pequenas cidades ${ }^{4}$. Os bens de produção e insumos, mas também os bens de consumo e os serviços, como educação, saúde e financeiros, são adquiridos numa verdadeira "...rede de centros de distribuição de bens e serviços" (CORRÊA, 1988, p.116). Paralelamente, a partir desses centros de acumulação de capital e poder difundem-se ainda valores e ideias que, por sua vez, provocam mudanças de caráter qualitativo, estando estruturadas segundo os principais escalões da rede urbana, de modo a corroborar com as próprias condições de reprodução desses mecanismos e com o processo de urbanização. De acordo com Clark (1991, p.101), "...de início, essas mudanças estão restritas e são experimentadas por aqueles que realmente residem na cidade, mas, com o passar do tempo, são difundidas e adotadas por aqueles que vivem nas áreas rurais, de tal modo que o conjunto da sociedade vem a ser dominado por valores, expectativas e estilos de vida urbanos".

Trata-se de um mesmo processo autoalimentador, no qual os centros de acumulação de capital e poder impõem-se aos centros sucessivamente subordinados e ao campo, numa evidente rede de trocas desiguais, assegurada, de um lado, pelo desenvolvimento de redes produtivas, mercantis e financeiras, caracterizadas pela ação dos agentes econômicos, particularmente, das "...grandes corporações multifuncionais e multilocalizadas", que "...desempenham poderoso papel na (re)definição funcional dos centros e na natureza e intensidade da integração de cada rede na economia global", como aponta Corrêa (2001, p. 95); e, de outro lado, pela difusão de um ideário urbano-moderno.

Esses circuitos de exploração efetuam-se, como sugere Corrêa (1989, p. 75), por meio de "...um multivariado processo de criação, apropriação e circulação dos valores excedentes". A drenagem desses valores é comandada naqueles centros de acumulação de capital e poder que estão no topo da hierarquia de um determinado segmento da rede urbana, que se apresenta, segundo Corrêa (1988, p. 116), como "...uma rede de drenagem de lucros", em decorrência dos processos desiguais de apropriação desses valores e sobre-valores, cujos desdobramentos resultam em profunda diferenciação entre os centros urbanos. Harvey (1980, p.204), a esse respeito, argumentou que "...as cidades [e suas respectivas redes] podem ser consideradas como formas criadas para a mobilização, extração e concentração geográfica de quantidade significativa do produto excedente socialmente definido". Nessa mesma lógica, Fredrich e Davidovich (1982, p. 541) observam que os centros urbanos são modelados "...pelas necessidades da acumulação de capital". Assim, esses circuitos são importantes para determinar a diferenciação geográfica, pois assumem uma dimensão espacial notória, que envolve os centros de financiamento, as áreas produtoras, os pontos de recebimento e armazenamento da produção, os centros de beneficiamento e processamento industrial e os centros de distribuição e comercialização, cada vez mais dispersos, porém inseridos na divisão territorial do trabalho, expressando, dessa maneira, uma óbvia distinção entre as aglomerações urbanas, entre estas e o 
Proposições para a análise da diferenciação espacial nos estudos sobre

sobre rede urbana: as noções de convêrgencia e divergência, pp. 34 - 58

campo, e entre as diversas redes envolvidas na dinâmica de acumulação de capital.

Em síntese, é na estrutura espacial das redes urbanas, destacadamente nos seus principais centros, que ocorre a apropriação de uma parcela desproporcional dos benefícios da divisão territorial do trabalho. Nesse sentido, observa-se que os circuitos de acumulação são tanto mais complexos quanto mais complexa for a divisão territorial do trabalho, que se amplia gradativamente entre os centros urbanos, principalmente pelas numerosas especializações produtivas, sejam na indústria, no comércio ou nos serviços, que, aliadas às funções preexistentes, resultam em uma importante complexidade funcional, que, por sua vez, intensifica a vida de relações, articulada, em muitos casos, numa lógica global. As especializações têm um efeito abrangente, sendo responsáveis por diferenciações em escalas regionais, nacionais ou mesmo internacionais. Dessa forma, o papel das especializações na requalificação dos centros e da própria rede urbana torna-se fundamental, assim como o das interações espaciais, que se transformam em componente essencial para a análise da diversidade das redes urbanas, posto que, como sugere Corrêa (1997, p. 295), "...apresentam padrões distintos no espaço e no tempo", sendo caracterizadas "...por lógicas que Ihes conferem regularidades espaço-temporais que se reportam à organização social e a seu desigual movimento de transformação".

Os centros de acumulação de capital e poder transformam-se, mormente, em centros de gestão, capazes de exercer notável comando sobre as atividades, as informações e sobre o espaço, em escalas distintas. Tal controle segue uma hierarquia, concentrando-se, primordialmente, nas metrópoles e, secundariamente, nos centros regionais, sugerindo, portanto, um fortalecimento das estruturas hierárquicas. Contudo tais hierarquias não são estáveis, dependem, sobretudo, dos mecanismos de competição e cooperação entre os centros, que são responsáveis por uma profunda distinção funcional, assim como pela diferenciação crescente das interações espaciais, definidas a partir das próprias funções desses na rede urbana.

A diferenciação crescente entre os centros urbanos resulta, em grande parte, da competitividade existente, cujas relações são de caráter hierárquico e divergente. Tal competição é amplamente acirrada pelas estratégias das empresas comerciais e de prestação de serviços, que atuam, sobretudo, organizadas em rede. Por outro lado, a interdependência entre as empresas, também incluídos os ramos industrial e agroindustrial, gera uma crescente cooperação entre os centros urbanos, resultando numa situação convergente, que, em síntese, privilegia interações complementares e a interdependência funcional. Num contexto regional especializado, identifica-se uma diminuição relativa da importância das interações entre os centros e suas hinterlândias e, ao mesmo tempo, uma crescente interdependência e complementaridade entre vários centros distintos, de regiões e, até mesmo, de países diferentes, chegando, provavelmente, ao que Veltz (1999) denominou rede-arquipélago de importantes centros. Tal fato aumenta a distinção entre os centros regionais e as aglomerações de suas respectivas hinterlândias, pois, enquanto esses centros regionais conectamse às redes em âmbito nacional e, até mesmo, internacional, suas hinterlândias passam a desempenhar funções cada vez mais subordinadas, demonstrando ações internas divergentes. Esses centros regionais, impulsionados por suas elites dirigentes e econômicas, estruturam-se para competir na economia nacional e também na internacional, com base numa interatividade que rompe com os padrões espaciais pretéritos.

O padrão espacial das redes urbanas está, portanto, submetido às constantes mudanças nos mecanismos de competição e cooperação entre os centros. Tais mecanismos são, igualmente, responsáveis pela diferenciação crescente entre os próprios centros, muitas vezes, historicamente cumulativa e tendencialmente linear e, outras vezes, atuando no sentido de reverter as hierarquias estabelecidas, especialmente mediante as iniciativas de elites empreendedoras, que desequilibram a situação 
costumeira da rede. Desses processos, que traduzem relações de trocas desiguais, resulta a complexidade da rede urbana, diretamente associada à própria complexidade da divisão territorial do trabalho. O aprofundamento da divisão territorial do trabalho e a ampliação exponencial das interações promovem mudanças nos conteúdos e nas formas espaciais. Em realidade, quando uma nova divisão territorial do trabalho se impõe, seja pela ampliação das funções produtivas, tanto agropecuária quanto industrial, seja pelo aumento das funções comerciais e de prestação de serviços, incluindose, primordialmente, as atividades especializadas, com um necessário aprofundamento das interações espaciais, desenha-se uma nova rede urbana, com funções e relações mais complexas e, desse modo, ocorrem diferenciações cada vez mais evidentes entre os centros urbanos e suas redes. Tal complexidade envolve a ampliação da esfera produtiva e do setor terciário, além da própria ampliação do consumo, gerando mudanças nos mecanismos de oferta e demanda de bens e serviços, o que, consequentemente, altera os circuitos de exploração, posto que a divisão do trabalho entre os centros urbanos torna-se muito mais complicada, privilegiando a diferenciação quanto mais aprofundada a divisão territorial do trabalho numa dada rede tanto mais diversos são seus centros.

De fato, os centros competem e cooperam em diferentes escalas, criando uma multiplicidade de fluxos, caracterizados por "...diversos tipos de interações e de redes geográficas que não são excludentes entre si", mas que certamente podem ser "...distintamente variáveis em termos espaciais e temporais", como aponta Corrêa (1997, p. 295), bem como definidos por horizontalidades, caracterizadas por interações fortemente regionais, e por verticalidades, que superam a continuidade geográfica, demonstrando a importância das relações extrarregionais, como sugere Santos (1993, 1994), que define os fluxos segundo esses dois recortes espaciais. Possibilitadas pelo aperfeiçoamento dos sistemas de transporte e comunicação, essas interações entre os centros criam e recriam configurações novas para a rede urbana, ora pela competitividade, ora pela cooperação, ou ainda, pela justaposição entre ambas. Se a relação de complementaridade se enfraquece e a de competitividade torna-se mais forte, amplia-se a diferenciação. Desse modo, conforme a concorrência se intensifique ou se enfraqueça, hierarquias urbanas podem ser misturadas ou homogeneizadas e, até mesmo, revertidas no sentido da re-diferenciação, de modo que a evolução e o padrão dessas redes estão sujeitos às constantes mudanças entre esses mecanismos, apoiadas basicamente em processos convergentes e divergentes.

\section{3 - As racionalidades convergentes e divergentes da diferenciação espacial}

Convergência e divergência são noções tomadas emprestadas de outros campos das ciências sociais, primordialmente das econômicas e das socioantropológicas. A adoção delas pela Geografia é bastante previsível, posto que essas noções referem-se à dialética entre semelhança e diferença, continuidade e descontinuidade, singular e universal e, naturalmente, espaço e tempo. Dessa forma, a proposição que se segue revela uma investigação orientada pela construção de um paralelo entre as visões economicistas e socioantropológicas, pois se faz necessário ater-se, em primeiro lugar, à objetividade dos conceitos e à possibilidade de delimitação das articulações e das analogias entre tais conceitos e o objeto investigado, e, em segundo lugar, destacar a importância fundamental das implicações espaciais e temporais, de modo a ampliar as visões economicistas e socioantropológicas.

Nas ciências econômicas, os estudos sobre convergência-divergência enquadram-se nas questões acerca da trajetória esperada de crescimento e desenvolvimento econômico de longo prazo, essencialmente entre países e entre regiões, ou melhor, entre conjuntos de economias, seja em nível internacional ou inter-regional. Tais estudos encontram-se apoiados no instrumental teórico e analítico expresso nos modelos neoclássicos de crescimento econômico e nos 
Proposições para a análise da diferenciação espacial nos estudos sobre

sobre rede urbana: as noções de convêrgencia e divergência, pp. 34 - 58

conceitos de equilíbrio, baseados na obra de Solow (1956), e nas Novas Teorias do Crescimento Endógeno, cujas raízes se encontram na obra de Gerschenkron (1962) e, recentemente, nas pesquisas de Barro e Sala-i-Martin (1992), Abramovitz (1986), dentre outros. Nessas pesquisas, a trajetória de crescimento e desenvolvimento econômico de longo prazo orienta-se ora num sentido convergente, contribuindo para configurar, entre os grupos de economias, forte tendência ao equilíbrio e à unidade, considerando situações ideais de atuação das forças de mercado; ora num sentido divergente, resultando em uma diversificação entre os grupos de economias, configurando, consequentemente, uma situação desequilibrante, quer dizer, que se realimenta da desigualdade, da instabilidade, tendo em vista que os mecanismos de mercado não atuam de forma a garantir uma situação de equilíbrio e de continuidade dos processos, mesmo em longo prazo. Assim, convergência e divergência representam, nos estudos econômicos, duas interpretações sobre a dinâmica evolutiva do crescimento e desenvolvimento econômico entre grupos de economias que determinam configurações para o equilíbrio/homogeneização ou para o desequilíbrio/heterogeneização, respectivamente.

Nas ciências socioantropológicas, a teoria da evolução sociocultural orienta os estudos sobre o desenvolvimento desigual das sociedades, bem como as análises sobre as formas de superação do atraso com que se defrontam algumas dessas sociedades. Tais debates, segundo Ribeiro (1979) e Sztompka (1998), estão apoiados no evolucionismo clássico, a exemplo dos estudos de Morgan; no neoevolucionismo, a exemplo das pesquisas de Childe, White e Steward; no materialismo histórico, a exemplo dos estudos de Engels e Marx; e também em estudos contemporâneos, dentre estes os de Wallerstein (2001), Touraine (1999, 1998), Giddens (2002, 1991), Elias (1990) e outros ${ }^{5}$.

De modo geral, tais estudos norteiamse pela discussão da mudança social, que se imprime diferencialmente sobre as sociedades, resultando em desenvolvimento desigual, pensada numa perspectiva evolucionista, em termos multilineares e fundamentada na noção de causalidade necessária, já que fatores causais, sejam por imperativos, condicionamentos ou contingenciamentos, conduzem as sociedades à perpetuação ou à mudança de suas formas e estruturas ${ }^{6}$. Nesse sentido, a explicação dos processos de mudança social deve ser buscada, primeiramente, nos fatores dinamizadores da transformação, isto é, "nas forças geratrizes"; e, em seguida, "nas condições sociais" sobre as quais tais forças operam, ou seja, nos condicionamentos provenientes dos contextos histórico-geográficos precedentes e dos contextos então vigentes, valendo frisar que a realidade social "...tem como característica principal a sua natureza de produto histórico", como salienta Ribeiro (1970, p.25). Essas forças geratrizes, comumentemente associadas à dinâmica universal da evolução, isto é, explicadas como resultado de processos históricos gerais de transformação, que atingem variavelmente as sociedades, e esses condicionamentos, sobre os quais tais fatores gerais atuam, portanto, relacionados com as dinâmicas singulares e particulares, são "...susceptíveis de acarretar o surgimento e a perpetuação dos extremos de atraso e de progresso". Nesse sentido, como sugere Ribeiro (1970, p.26), a evolução das sociedades está orientada por "...efeitos divergentes e convergentes", haja vista que elas experimentam dois processos simultâneos e complementares de autotransformação, de modo que um é dado pela inevitável evolução social e responsável pela homogeneização, por conseguinte, associado ao plano universal; e o outro responde pela diversificação ou diferenciação, associado aos planos singulares e particulares. Ressalta-se que o processo com caráter diversificador ou divergente, de acordo com Ribeiro (1979, p.36), "...colore com qualidades particulares a cultura de cada sociedade, especializando-a a certo ambiente ou desviando o rumo do seu

Em realidade, no que diz respeito aos processos de convergência e divergência, existem quatro combinações possíveis, em se considerando a fixidez de um dado contexto espacial e de um determinado intervalo de tempo, de duração a 
priori indeterminada, nas quais predominam um ou outro processo, caracterizando fases convergentes ou fases divergentes. Nessa circunstância, pode-se lançar mão de um conjunto de esquemas, como retratado na Figura 1, na qual as realidades $A$ e $B$ estão indicadas em tempos distintos, $T_{1}$ e $T_{2}$, em que a linha representa um espaço-tempo, que consiste numa representação intelectual do movimento ou do ritmo da mudança, de modo que em $T_{1}$ inicia-se a atuação dos processos de convergência ou de divergência. Da combinação desses processos resulta a realidade em $\mathrm{T}_{2}$, composta dos acréscimos históricosgeográficos sobre o legado em $\mathrm{T}_{1}$. Assim, na primeira linha, observa-se o par convergênciadivergência, isto é, o processo parte de uma situação homogênea, A-B, e chega a uma condição de diferenciação, A e B, em posições distintas, por meio de eventos predominantemente divergentes. Contrariamente, na segunda linha, visualiza-se o par divergência-convergência, ou seja, a partir de condições distintas, A e B são encaminhados para uma situação de similitude, $A-B$, pois prevalecem os efeitos convergentes. Nesses casos, observa-se uma descontinuidade dos processos, com diferenciais nas trajetórias. $\mathrm{Na}$ combinação desses dois processos, têm-se ainda as situações de homogeneidade absoluta e de diferenciação igualmente absoluta, nas quais prevalecem de forma irrestrita os processos em curso. De sorte que, na terceira linha, os processos em parceria são convergência-convergência e resultam na condição $A-B$, indicando a perpetuação ou a continuidade de uma realidade unitária. Na quarta linha, o par é divergênciadivergência, que tem como resultado a permanência das situações distintas, A e B. Notase, pois, que tais processos estão diretamente vinculados ao movimento e à transformação, porque, de um lado, as mudanças com descontinuidade derivam da interação entre processos contraditórios, da oposição entre um e outro, marcados pela mutação, uma vez que as forças de oposição impelem geralmente na direção contrária7; e, de outro lado, as mudanças com continuidade derivam de processos estáveis, cujo resultado é a conservação ou perpetuação, diante de forças homogeneizadoras, de modo a revelar a duração de espaços-tempos, nos quais o tempo perpassa o espaço que, por sua vez, expande e contrai o tempo, num movimento constante e ininterrupto. Nas palavras de Giddens (2002, p.10), "...a vida social moderna é caracterizada por profundos processos de reorganização do tempo e do espaço..." que atuam "...na transformação do conteúdo e da natureza da vida social cotidiana"8

\begin{tabular}{|c|c|c|}
\hline Processos para A e B & $\mathrm{T}_{2}$ & Natureza da mudança \\
\hline Convergência-Divergência & $\begin{array}{l}\mathrm{A}-\mathrm{B} \longrightarrow \mathrm{A} \\
\longrightarrow \mathrm{B}\end{array}$ & \multirow[t]{2}{*}{ Mudanças com descontinuidade } \\
\hline Divergência-Convergência & $\mathrm{A} \longrightarrow \mathrm{A} \longrightarrow \mathrm{B}$ & \\
\hline Convergência-Convergência & $\mathrm{A}-\mathrm{B} \longrightarrow \mathrm{A}-\mathrm{B}$ & \multirow{2}{*}{ Mudanças com continuidade } \\
\hline Divergência-Divergência & $\begin{array}{l}\mathrm{A} \longrightarrow \mathrm{A} \\
\mathrm{B} \longrightarrow \mathrm{B}\end{array}$ & \\
\hline
\end{tabular}

Figura 1 - Possibilidades de combinação dos processos de convergência e divergência, em um dado contexto espaço-temporal. Org.: BESSA, 2007 
Proposições para a análise da diferenciação espacial nos estudos sobre

sobre rede urbana: as noções de convêrgencia e divergência, pp. 34 - 58

Contudo, como salienta Smith (1988), a estrutura social e também o espaço não são homogeneizados fora da existência, por meio de processos de convergência absoluta, que resultariam numa a-espacialidade ${ }^{9}$; e nem são diferenciados infinitamente por intermédio de efeitos divergentes, como ressaltados na Figura 2. Tais processos não existem em si mesmos e nem são absolutos. Antes, esses processos estão profundamente imbricados e, sobretudo, associados a uma descontinuidade sistêmica, em que países, regiões, centros urbanos ou mesmo empresas e instituições podem apresentar reversão na convergência, pela estática ou inércia presente, acentuando os desequilíbrios com o aumento das pressões competitivas, resultando em divergências que, em alguns casos, refletem características conjunturais locais ou contingências, a exemplo do desempenho econômico favorável acionado pelas práticas inovadoras de elites empreendedoras. Em vista disso, seria enganoso esperar que as trajetórias de países, regiões, centros urbanos pudessem ser reduzidas a um modelo formal, como no caso dos modelos econômicos. Por outro lado, é temerário apostar no caráter direcional e homogeneizador das amplas teorias de evolução sociocultural, pois a realidade, em suas singularidades e particularidades, apresenta importante tendência variante, fazendo-se necessário, como observa Giddens (1991), desconstruir a narrativa do evolucionismo para, dessa maneira, identificar as descontinuidades e indagar sobre o ritmo e o escopo da mudança, assim como sobre sua natureza intrínseca ou extrínseca.

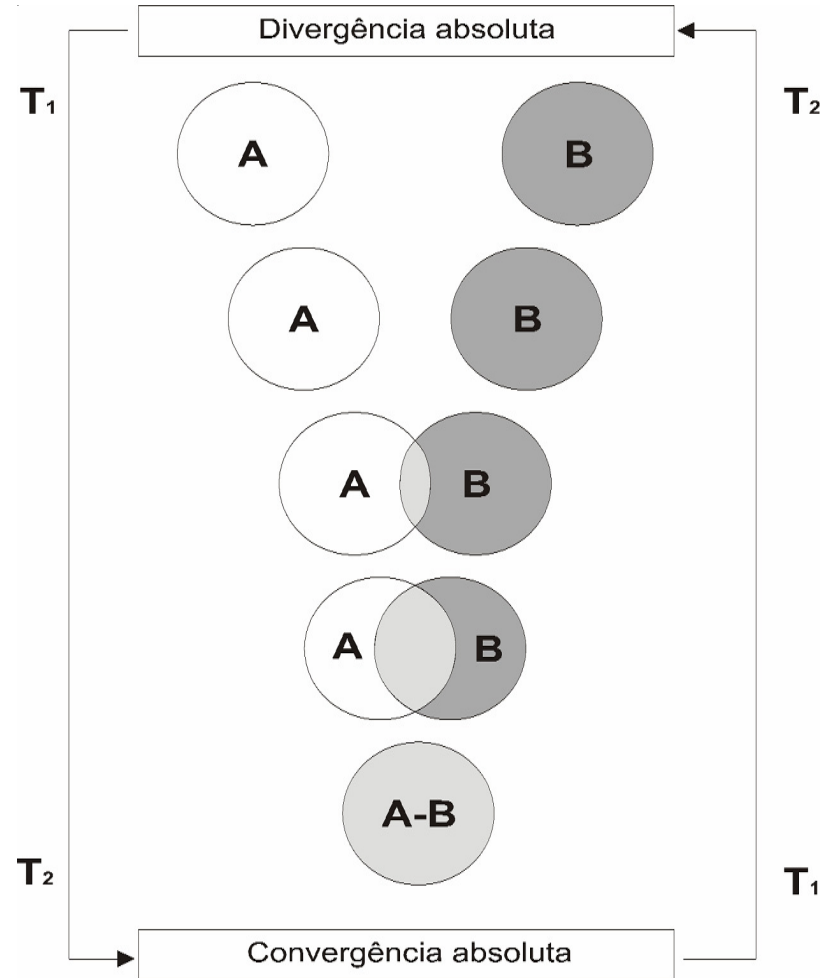

Figura 2 - Processos de divergência-convergência/ convergência-divergência, num contexto de absolutização. Org.: BESSA, 2007. 
Desse modo, não há equilíbrio duradouro no sentido de condições socioespaciais homogeneizadas. Mesmo em condições iniciais semelhantes, os eventos, especialmente sob a lógica capitalista, apesar de tendencialmente homogeneizante, irão promover a diferenciação ${ }^{10}$, que poderá ser mantida por certo tempo, dependendo das estratégias de permanência e de reiteração da situação posta, ou seja, das estratégias de resistência das situações enraizadas. Até que novos eventos, orientados sobretudo por processos opostos, alavanquem o processo de convergência. Em se estabelecendo novamente a situação de homogeneidade, as chances de reversão são significativas, pois quem impulsionou o processo permanecerá com movimento positivo, ao contrário daquele que está vinculado aos processos de permanência, que geram estancamento e, provavelmente, regressão. A tendência à diferenciação emerge novamente, pois existe, na verdade, um equilíbrio sempre mutável entre os efeitos de convergência e os efeitos de divergência.

Nesse sentido, faz-se necessário construir uma ampla abordagem histórica e geográfica para essas questões. Tal perspectiva abre possibilidades para considerar, fora do quadro analítico de equilíbrio estático e universalizante dessas teorias, a formação, a natureza e a trajetória real desses processos, correlacionando as fases de convergência com as fases de divergência no sentido de explicar a evolução desigual, que deriva da assincronia desses processos, e de tornar inteligível o equilíbrio sempre mutável ou a descontinuidade sistêmica entre tais processos, cujos embates ocorrem principalmente nas escalas do singular e do particular. Martin e Sunley (2000) propõem estudos históricos mais contextualizados, que sejam mais sensíveis aos detalhes e às especificidades de cada lugar particular e que busquem analisar as verdadeiras raízes da diferenciação espacial, especialmente naquelas situações de reversão, nas quais se destacam as mudanças de convergência para a divergência ou de divergência para a convergência, que resultam em re-diferenciação; assim como naquelas que mantenham a continuidade dos processos. Assim, faz-se necessário historicizar os contextos, quer dizer, orientar-se pelo entendimento da mudança histórica, bem como captar a importância dos agentes econômicos, políticos e sociais, assim como das estruturas institucionais, primordialmente daqueles que apresentam habilidades em promover ou absorver as inovações, sejam elas tecnológicas ou organizacionais. Igualmente, faz-se necessário espacializar tais processos, uma vez que o espaço constitui-se em reflexo, meio e condição.

Entre os modelos de crescimento e desenvolvimento e a abordagem da Geografia, existem nítidas diferenças em termos de teoria e de método. Primeiramente, porque a dimensão espacial dificilmente pode ser enquadrada em modelos formais de crescimento, fundamentados em concepções matemáticas, com análises estatísticas extensivas, que desconsideram a "...importância da contingência geográfica" e que conflitam com a "...concepção geográfica de diversidade e de especificidade", como sugerem Martin e Sunley (2000, p.33). Além disto, há que se ponderar que os elementos-chave considerados nos modelos de crescimento endógeno - retornos crescentes de capital, formação de capital humano e progresso tecnológico - atuam desigualmente no espaço, assim como são espacialmente diferenciados, produzindo diversidade territorial. Esses elementos podem inclusive fluir de um lugar para outro, de acordo com os interesses dos agentes econômicos, e, dessa forma, acentuar os desequilíbrios. Os lugares, por sua vez, podem ser reabilitados. A implicação espacial ou variação espacial, tomando emprestados os termos de Thrift (1996), ou ainda, ajustes espaciais, expressão usada por Harvey (2004), é dado fundamental ${ }^{11}$. Por outro lado, as práticas e as estratégias dos agentes são imprevisíveis e também são dados essenciais que permitem interpretar a constituição e a diferenciação do espaço. Há que se levar em conta que tais modelos deixam de historicizar e geografizar as mudanças, tornando-se, dessa forma, inadequados para o seu entendimento, pois pouco dizem sobre a natureza, o ritmo e o escopo da mudança. Nesse sentido, tais modelos tornam-se incapazes de revelar os processos envolvidos na trajetória de crescimento, 
Proposições para a análise da diferenciação espacial nos estudos sobre

sobre rede urbana: as noções de convêrgencia e divergência, pp. 34 - 58

pois "...vêem-se constrangidos por sua adesão a um quadro analítico de equilíbrio que impõe muitas e importantes limitações", como referem Martin e Sunley (2000, p.33). Esse quadro analítico de equilíbrio estático formal impossibilita a apreensão dos contextos histórico-geográficos que conformam os processos de mudança. Além disto, negligencia a atuação plural dos agentes econômicos, políticos e sociais, assim como não esclarecem como tais atuações correlacionam-se com os períodos de convergência e de divergência. Vale ressaltar que muito pouco é dito sobre como o processo de crescimento é dirigido, encorajado ou restringido, ou ainda, sobre como a capacidade social é determinada e como se desenvolve ao longo do tempo, apesar de ocuparem papéis fundamentais nesses modelos. Desconsidera também os investimentos estrangeiros e as atividades e intervenções do setor público. Enfim, tais modelos negligenciam a preeminência dos contextos, além de julgar que o êxito econômico repousa sobre um conjunto de fatores comuns.

Os estudos socioantropológicos, por sua vez, procuram explicar a evolução sociocultural como resultado de imperativos e condicionamentos, supostamente, universais e direcionais, desconsiderando os processos históricos e geograficamente específicos e contingentes. Embora a explicação seja pertinente, no plano universal, ela tende a deixar em segundo plano a indispensável sensibilidade histórico-geográfica. Trata-se, realmente, disto, os aspectos universais não se inserem de forma homogênea, pelo contrário, fazem-no de forma incompleta, seletiva e desigual, cujo exemplo mais notório é, atualmente, a globalização. Dessa maneira, o próprio movimento universalizante produz diferenciação e desigualdade, e, por isto, a pertinência da lei do desenvolvimento desigual e combinado, diretamente vinculada aos aspectos hegemônicos. Por outro lado, os contextos, já bastante diferenciados, como resultado de outras justaposições, reagem a essa inserção de forma simétrica ou assimétrica, sendo a diversidade socioespacial resultado da articulação entre características da diferenciação espacial prévia e as necessidades prementes das forças hegemônicas. Por efeitos convergentes, os contextos alinham-se à dinâmica universal, no sentido de atender, mais prontamente, ao seu movimento, garantindo uma homogeneização relativa e sua consequente inserção. Por efeitos divergentes, os contextos conflitam ou mesmo negam o movimento universalizante, hegemônico, produzindo uma diversidade efetiva, que se traduz não apenas em desigualdade, mas, sobretudo, em diferença qualitativa, em distinção. Destarte, a leitura da formação socioespacial, da região, do território e do lugar são dados relevantes para tornar inteligível essa diferenciação, cujas implicações são potencialmente divergentes.

Há, de fato, muitas questões envolvidas nessa problemática, baseadas essencialmente nas contradições e antagonismos do mundo social. Para cada autor que enfatiza a eliminação das diferenças e a universalização das ações convergentes, inclusive argumentando sobre o fim do espaço, há outro autor que destaca o aumento das diferenças e seus efeitos divergentes sobre a estrutura socioespacial, notadamente sob a égide da globalizaçãofragmentação, desfazendo a tese que sustenta a indiferenciação espacial ${ }^{12}$. Contudo uma das explicações mais valiosas está na identificação da dinâmica relacional e contraditória entre os processos igualizadores, inerentes aos imperativos universalizantes, com forte tendência à homogeneização, por meio de efeitos convergentes, e os processos diferenciadores, surgidos no interior das formações socioespaciais, com tendência à diversidade, por meio de efeitos divergentes. A complexidade da estrutura socioespacial resulta dessa dinâmica relacional e contraditória, determinada pelas tendências opostas, porém, combinadas, para a igualização e para a diferenciação, para a homogeneidade e para heterogeneidade, como resultantes da assincronia entre os processos convergentes e divergentes, respectivamente. Outra explicação de importância relevante está no entendimento de que tal contradição tem uma dimensão espacial premente - a diferenciação espacial, pois essas tendências opostas, juntas, produzem uma geografia específica, que passa a ser dado vital. De fato, essa contradição se expressa espacialmente por meio da diferenciação do 
espaço geográfico, que possui base natural e social, fundamento qualitativo e quantitativo, que exprime atualmente a dinâmica global-local, assim como se apresenta sob muitas formas, inclusive, sob o padrão notório de desenvolvimento espacial desigual, mas que fundamentalmente é expressão e condição das múltiplas dinâmicas sociais. Tratase de questões imbricadas, posto que da dialética entre convergência e divergência resulta a síntese dos contrários: a diferenciação espacial.

A diferenciação do espaço geográfico é manifestação concreta e, ao mesmo tempo, é processo dessa dinâmica contraditória entre os aspectos convergentes e divergentes, a partir dos quais a indiferenciação do espaço não passa de um mito. Na sua aplicação na Geografia, a noção de diferenciação espacial possui, por conseguinte, uma reflexividade prático-empírica, pois os conteúdos da diferença na paisagem, no lugar, no território, no espaço são absolutamente reais, concretos. Por outro lado, têm uma reflexividade teórica e metodológica, porquanto se impõe a necessidade de refletir o problema de ser a diferenciação espacial essencial à natureza da Geografia.

Desse modo, as noções de convergência e divergência, que resultam em padrões de igualização e diferenciação, podem ser agregadas aos estudos geográficos e, especificamente, aos estudos sobre rede urbana, porque, em ambos os casos, a incessante mudança nos conteúdos e nas formas espaciais obriga a uma renovação das categorias de análise, no sentido de aprofundar a explicação e de determinar a natureza dos processos. Nesse sentido, tais noções possuem poder explicativo suficiente para dar conta da complexidade das mudanças que envolvem as transformações dos padrões espaciais da rede urbana, até mesmo com relação à natureza dos processos de diferenciação entre os seus centros. Entretanto, diante dessa complexidade de posições teórico-conceituais, tornam-se fundamentais as correlações com as questões pertinentes aos estudos sobre rede urbana, mormente sobre os processos de diferenciação entre os centros e as suas respectivas redes. Nos trabalhos relevantes acerca da rede urbana brasileira, destacam-se os de
Monbeig (1943), Deffontaines (1944), Rochefort (1961), Corrêa (2006, 2004, 2001, 2000, 1989, 1988, 1967), Geiger (1963), Santos (1993, 1979, 1967), Davidovich (1989, 1978), Davidovich e Lima (1976, 1975), Fredrich e Davidovich (1982), Faissol $(1975,1973)$, dentre outros.

\section{4 - Re-diferenciação entre Uberaba e Uberlândia (MG)}

As transformações sucessivas do padrão espacial do segmento da rede urbana no Triângulo Mineiro são bastante ilustrativas no que diz respeito aos contornos gerais que caracterizam os processos de diversificação da rede urbana brasileira, em que novas diferenças e hierarquias impõem-se a cada espaço-tempo, em decorrência das práticas socioespaciais das elites locais, das grandes corporações e do Estado. Em realidade, tais transformações não são derivadas de um simples resultado inintencional, praticado aleatoriamente por agentes desconhecidos. Antes, ocorrem sob a liderança das elites e as pressões das grandes corporações, com o aval do Estado. Nessa perspectiva, as noções de convergência e divergência são dados que permitem interpretar os processos de reatualização da rede urbana triangulina, auxiliando não apenas na compreensão dos fatores deflagrantes de uma completa reestruturação dessa rede, que envolveram a desvalorização da posição relativa de Uberaba e a valorização da posição de Uberlândia, mas, sobretudo, na compreensão de quem aciona os processos e qual a natureza de tais processos, que definiram dois espaçostempos distintos: o espaço-tempo da convergência e o espaço-tempo da divergência, como observado na Figura 3, reveladores dos amplos processos de mudança socioespacial, cujas origens, as determinações, as coerências e os efeitos exigiram análise criteriosa.

Uberaba despontou como principal centro urbano da região ainda na primeira metade do século XIX, em decorrência de uma diferenciação definida pela atividade pastoril, que possibilitou um acúmulo de funções diretamente ligadas à comercialização da produção 
Proposições para a análise da diferenciação espacial nos estudos sobre

sobre rede urbana: as noções de convêrgencia e divergência, pp. 34 - 58

agropecuária, orientando uma primeira fase de estruturação da rede urbana regional, quando Uberlândia era simplesmente um arraial indiferenciado do próprio termo de Uberaba. A partir do final do século XIX, mas especialmente ao longo da primeira metade do século $X X$, novos eventos, orientados por fatores internos e externos, criaram as variáveis que promoveram mudanças nesse arranjo espacial, resultando, primeiramente, numa segunda fase de estruturação dessa rede marcada pela ascensão de outros dois centros, Araguari e Uberlândia, e, posteriormente, numa terceira fase, caracterizada pela dualidade entre Uberaba e Uberlândia, quando se apresentaram praticamente indiferenciados, sendo possível traçar alguns paralelos, posto que eram semelhantes em termos populacionais e funcionais e também relativamente similares na sua complexidade política, econômica e social. Hoje, no entanto, esses centros estão profundamente diferenciados entre si, uma vez que respondem por relações socioeconômicas distintas, sendo Uberlândia o principal centro urbano regional em substituição ao que foi no passado Uberaba, expressando uma nova fase de estruturação da rede urbana regional. A evolução da estrutura urbana no Triângulo Mineiro, em seus traços mais gerais, processou-se em quatro fases, que assumem dimensões espaciais específicas. Na fase atual, o dinamismo presente em Uberlândia deixou relativamente marginalizado o antigo centro regional.

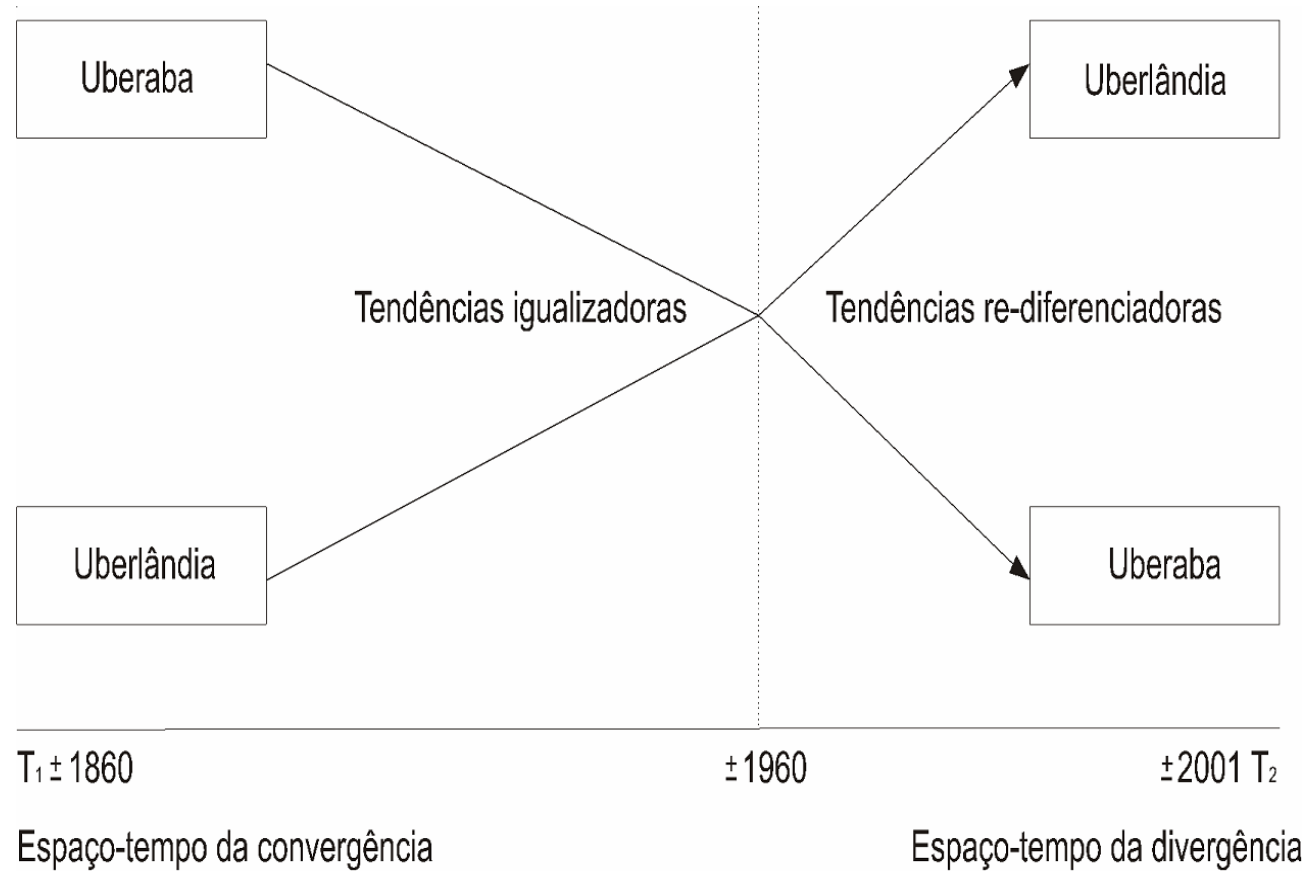

Figura 3 - Esquema interpretativo dos processos de convergência-divergência entre Uberaba e Uberlândia, que resultaram na re-diferenciação e na inversão hierárquica. Org.: BESSA, 2007.

A partir do final do século XVIII, a pecuária passou a definir, efetivamente, o papel do Triângulo Mineiro, garantindo sua inserção na divisão territorial do trabalho e estruturando um embrião de rede urbana ainda na primeira metade 
do século XIX. Essas racionalidades promoveram a diferenciação de Uberaba, cuja posição derivou de condições específicas, definidas em momentos particulares, resultando em uma posição de primazia urbana regional.

Anteriormente, com os núcleos iniciais de povoamento, não se formou, de forma efetiva, uma rede de arraiais, pois a região não estava inserida numa divisão territorial do trabalho e não havia uma economia de mercado na qual estivesse incluída, por meio do intercâmbio regular de mercadorias. Tratava-se de uma área de circulação, sem articulação alguma da vida regional. Com a mineração, Desemboque diferenciou-se dos demais núcleos e estabeleceu intercâmbios com relativa regularidade, porém não havia outras atividades capazes de gerar interações, estando o desenvolvimento mercantil limitado à atividade da mineração, e, ademais, não se estabeleceram com regularidade interações no interior da região, pela ausência de uma real divisão territorial interna do trabalho e, por esses motivos, aquele arraial não chegou a animar uma rede urbana propriamente dita.

Com desenvolvimento da pecuária, estabeleceram-se intercâmbios permanentes, tanto interna quanto externamente, criando, de fato, um embrião de rede urbana. Nessa fase embrionária da rede triangulina, diferenciaramse Araxá, Patrocínio e Uberaba, que iniciaram uma primeira fase de integração, uma vez que, com a pecuária, se impôs a necessidade do estabelecimento de circuitos comerciais regulares. As funções comerciais foram melhor incorporadas por aqueles centros mais aptos ou por aqueles que criaram essa aptidão, a exemplo de Uberaba, indicando conflitos de interesses entre as incipientes elites regionais, particularmente, entre Araxá e Uberaba. As estratégias das elites uberabenses foram mais empreendedoras, principalmente pela construção de uma infraestrutura de transportes e pela formação de novos arraiais, com os quais estabeleceu interações dissimétricas, criando, mesmo que de forma incipiente, uma vida de relações intrarregional. Também, por intermédio desses pequenos núcleos, notadamente Uberaba, a região integrou-se a duas redes - a de São Paulo e a do
Rio de Janeiro, esboçando um espaço de interações extrarregional. Nessa dinâmica, Uberaba apareceria cumprindo papel de centro regional e de intermediação entre o sertão e o litoral, com importante ampliação das funções comerciais, que convergiram no sentido de ampliar a sua diferenciação frente aos demais centros, gerando, dessa maneira, uma estrutura espacial duradoura e indispensável ao desenvolvimento da atividade pecuarista, pois, sobre as bases dessa economia pastoril, erigiu-se um centro comercial, que articulava internamente a região, assim como estabelecia interações externas pela comercialização do gado e do sal, principais produtos desse circuito comercial.

A diferenciação de Uberaba, nessa ocasião, deveu-se às ações empreendedoras de sua elite, que reestruturou as primitivas infraestruturas de transporte regional, definidas por caminhos e picadas em seu benefício, ampliando e reforçando sua posição relativa. Esse primeiro padrão de rede embrionária estava, portanto, diretamente associado à pecuária, ou seja, à atividade predominante na região, que atuou como um vetor interno da organização espacial triangulina. Uberaba, alicerçada pelas ações de sua elite empreendedora, concentrava o comando da principal atividade econômica regional, assim como detinha também o comando dos sistemas de transporte regionais, que, nessas circunstâncias, atuaram com efeito divergente, pois aceleraram a diferenciação de um núcleo urbano - Uberaba - em prejuízo dos demais, valorizando o seu papel como centro de organização do espaço regional. Dessa condição de comando, sobre o espaço e sobre a produção, emergiu a notável diferenciação de Uberaba e consolidou-se uma tendência à primazia urbana, pela concentração de população, de funções urbanas e de capitais. A área de influência desse centro alcançava toda a região triangulina e uma vasta área pecuarista, com as quais mantinha um movimento de trocas desiguais, pela sua capacidade de organização e controle. Os demais núcleos, com uma população pequena, ofereciam comércio e serviços mínimos e limitados.

Com o aperfeiçoamento dos meios de transporte, especialmente com a introdução da 
Proposições para a análise da diferenciação espacial nos estudos sobre

sobre rede urbana: as noções de convêrgencia e divergência, pp. 34 - 58

ferrovia e das estradas de rodagem, criou-se novas possibilidades de inserção e de interação nos territórios alcançados por essas infraestruturas. Num processo, cujas decisões não estavam mais diretamente associadas aos interesses exclusivos da elite uberabense, posto que a expansão da ferrovia, no Triângulo Mineiro, foi comandada pelos capitais paulistas e a expansão das estradas de rodagem por capitais uberlandenses, novos centros foram atingidos e, notoriamente, diferenciados dos demais. A partir do final do século XIX e, sobretudo, nas primeiras décadas do século $X X$, iniciou-se uma paradoxal convergência entre Uberaba, Araguari e Uberlândia.

No Triângulo Mineiro, a pecuária manteve-se ainda como a principal atividade regional, bem como foi responsável pela sua inserção na divisão territorial do trabalho, porém ampliaram-se e diversificaram-se as funções comerciais, especialmente nos pontos de intersecção entre as redes ferroviárias e de estradas de rodagem. Ao mesmo tempo, ocorreu a expansão de uma agricultura mercantil, para atender às demandas da população urbana, particularmente a paulista. Assim, com maior possibilidade de intercâmbios, criou-se uma divisão territorial interna do trabalho mais complexa, visto que Uberaba seguiu comandando a criação de gado, inclusive, com um refinamento da raça zebuína. Araguari e Uberlândia desenvolveram novos circuitos comerciais, com importante retenção de rendas e ampliação da área de atuação.

Notadamente, os meios de transporte, nesse momento, surgiram como os motores da reorganização espacial, atuando como um imperativo para convergência entre os principais centros urbanos no Triângulo Mineiro. Paradoxalmente, essa convergência entre Uberaba, Araguari e Uberlândia foi desencadeada pelo aperfeiçoamento da infraestrutura de transporte, que possibilitou a ampliação das atividades urbanas, com destaque para o comércio, e também a expansão das atividades agropecuárias, aumentando as interações espaciais, que, numa relação de causa e efeito, acabaram por fomentar ainda mais tais atividades, incorporando novos centros aos circuitos comerciais. De fato, esse conjunto de variáveis atuou no sentido de elevar a hierarquia de Araguari e Uberlândia, diferenciando-os dos demais centros elementares da região, relativamente homogêneos, e, ao mesmo tempo, no sentido de equiparar com Uberaba, o que impôs limites ao seu domínio regional, apesar dos investimentos industriais, principalmente na indústria alimentícia e de beneficiamento de produtos agropecuários.

A partir desse momento, inicia-se um significativo processo de competição entre esses centros. Tal competição ocorreu, primordialmente, na esfera comercial, posto que na pecuária Uberaba ainda se destacava, pois possuía o gado de melhor qualidade e também o maior plantel. Essa atividade passou a definir-se como uma importante especialização uberabense, indicando deficiências no sentido de criação e renovação de outras atividades, em particular, as de natureza urbana.

Os circuitos comerciais, a partir de 1920, com o aumento da comercialização da produção rural e da distribuição dos produtos industriais, passaram a operar como variávelchave da reorganização espacial no Triângulo Mineiro. A demanda gerada pelo crescimento urbano-industrial, mormente em São Paulo, possibilitou, de um lado, a expansão da agropecuária, e, de outro, um aumento no consumo de produtos industrializados, intensificando a vida de relações, ainda restrita à padrões, eminentemente, regionais. Em Uberlândia, pela constituição de um entroncamento rodoferroviário, criou-se um amplo circuito de comercialização e distribuição de mercadorias, que foi, gradativamente, superando as funções comerciais de Araguari e convergindo no sentido de se aproximar e superar as de Uberaba. Uberlândia tornou-se o pólo principal de acumulação do capital mercantil, abrindo, inclusive, possibilidades para o desenvolvimento industrial, caracterizado também pela indústria alimentar e de beneficiamento, assim como em Uberaba, indicando uma posição equivalente das estruturas produtivas. Nesse momento, tais centros caracterizavam-se como lugares centrais, primordialmente, pelas funções de 
comercialização da produção rural e pela atuação na prestação de serviços, porém, já envolvidos numa estrutura industrial, marcadamente, no ramo da indústria alimentar e de beneficiamento dos produtos agropecuários locais e regionais.

A partir de 1940, a competição entre esses centros urbanos tornou-se bastante acirrada, induzindo a uma ordenação espacial bastante hierarquizada. A pecuária e a agricultura estenderam-se por toda a região, aumentando a concorrência entre os centros de comercialização e de beneficiamento. Araguari, pela incapacidade de atuar no sentido de revitalizar e renovar suas atividades funcionais, bem como pela competição exercida por Uberlândia, Goiânia e Anápolis, não conseguiu assegurar sua posição, e a competição regional passou a ocorrer, primordialmente, entre Uberaba e Uberlândia. Uberaba, nitidamente voltada para as atividades pastoris, transformouse em um centro de drenagem e consumo da renda fundiária, quer dizer, graças às práticas absenteístas de seus proprietários rurais, grande parte da riqueza produzida no campo passou a ser consumida na cidade, à medida que ia ostentando um conteúdo urbano relativamente sofisticado, com arquitetura, equipamentos, comércios e serviços de luxo, que serviam a essa elite.

A diversificação econômica, apoiada no reaparelhamento infraestrutural do final da década de 1950, operou, desse período em diante, como elemento central da reestruturação espacial no Triângulo Mineiro. Há que se ressaltar que as acumulações de capitais, tanto na pecuária, quanto nos circuitos comerciais, permitiram investimentos na industrialização, especialmente na indústria de produtos alimentícios e de beneficiamento de produtos agropecuários, indicando importante complementaridade entre o rural e o urbano, assim como uma densificação das interações espaciais, que se realizavam, primordialmente, em escalas local e regional. Do ponto de vista industrial, Uberlândia, já em 1950, ocupava a primeira posição regional, tanto em número de estabelecimentos quanto nos valores da produção, indicando diferenciações na capacidade produtiva. A concentração das atividades comerciais, varejistas e atacadistas, em
Uberlândia, tornou-se visível também a partir dessa década.

Com a política de integração nacional, com os impulsos dados ao processo de interiorização e com a construção da nova capital federal, Uberlândia consolidou-se como centro de coleta, de beneficiamento, de comercialização e de distribuição de mercadorias para uma ampla região no Brasil Central, com um substancial aumento das interações espaciais, que resultou num acúmulo significativo de capital. No sentido oposto, estreitaram-se as relações com São Paulo. Esse centro, de fato, passou a concentrar as condições gerais da produção capitalista, e, ao fazê-lo, ampliou sua funcionalidade, que resultou da articulação das esferas da produção, da circulação e do consumo, garantindo, de um lado, importante diferenciação frente aos demais centros triangulinos, e, de outro, significativa igualização ante a Uberaba, que, até então, determinava as decisões regionais.

Desse modo, com a expansão uberlandense, desenha-se uma nova geografia dos comandos e das decisões da vida regional. Antes, com uma divisão territorial interna do trabalho menos densa, os controles regionais estavam associados à Uberaba. Porém, com a diversificação das atividades, que indicava uma divisão territorial interna do trabalho mais complexa, e com a densificação dos padrões de articulação espacial, determinada pelo aperfeiçoamento dos meios de transporte e de comunicação, Uberlândia apareceu exercendo papéis de controle sobre o espaço e sobre parcelas da produção regionais. Com o aprofundamento da divisão territorial interna do trabalho passou a ocorrer um revezamento dos controles no espaço regional, e, por conseguinte, parcelas de regulação ora eram ativadas em Uberaba ora em Uberlândia, indicando uma clara convergência dos processos urbano-regionais.

Tal convergência, no entanto, não se orientou por uma tendência de complementaridade e, sim, de divisibilidade, posto que não se pode falar em interesses comuns, ao contrário, a partir desse momento, verifica-se uma crescente diferenciação entre esses dois centros, que seguiram por caminhos específicos, resultando em uma distinção e, sobretudo, em uma 
Proposições para a análise da diferenciação espacial nos estudos sobre

sobre rede urbana: as noções de convêrgencia e divergência, pp. 34 - 58

reatualização da rede urbana regional, com mudanças na hierarquia, que sintetizam processos de recriação das diferenças espaciais, fruto de uma complexa alteração na divisão territorial interna do trabalho, com uma verdadeira refuncionalização desse território.

De fato, a rearticulação urbanoregional, ou melhor, a rearticulação que se opera nos centros urbanos de uma dada região, ocorre fundamentada em função de mudanças na estrutura socioespacial, ora subordinada às atividades tradicionais, ora subordinada às atividades ditas modernas, com uma nítida transformação estrutural no esquema produtivo. Contudo há que se acrescentar que a redefinição dos centros urbanos pressupõe a redefinição de elites, que, no caso em questão, passaram a convergir seus interesses para Uberlândia em detrimento de Uberaba. As novas formas de participação da região na divisão territorial do trabalho permitiram à Uberlândia aumentar seu comando sobre o espaço regional mediante uma polarização mais clara e mais forte que reduziu a importância relativa de Uberaba. A função de cidade regional, a partir de então, caberia a Uberlândia. Cumpre ressaltar que, até esse momento, o capital era predominantemente regional, sendo que as novas condições possibilitaram a entrada de capital extrarregional. O capital regional emergente, contudo cresceu para além dos horizontes da região, alterando as condições do crescimento econômico regional juntamente com a própria entrada do grande capital.

A primazia definitiva de Uberlândia ocorreu a partir dos anos de 1970, em consonância com os processos econômicos e sociais em curso no país. Em razão da capacidade de absorver os impulsos da economia nacional, em decorrência da facilidade de implantação de novas formas de organização das atividades produtivas, conseguida especialmente pela ausência de formas pretéritas, em função do desenvolvimento das atividades econômicas, Uberlândia assumiu posição de comando em prejuízo de Uberaba, que foi esvaziada de uma parcela de suas funções, principalmente as regionais, ocorrendo, a partir de então, uma dinâmica divergente na estruturação do espaço regional, que resultou na redefinição hierárquica entre tais centros.

As novas condições implicaram o esgotamento do padrão da rede urbana pretérita, pois, hoje, Uberaba e Uberlândia estão diferenciados entre si, uma vez que respondem por relações sócioeconômicas distintas, sendo Uberlândia o principal centro urbano do Triângulo Mineiro, em substituição ao que foi no passado Uberaba. No tempo em que concentrava e comandava a tradicional atividade econômica, a pecuária, que, até certo momento, definiu a especificidade produtiva e a posição da região na divisão territorial do trabalho, Uberaba manteve seu dinamismo urbano-regional. Com a reorganização da divisão territorial do trabalho, quando a região foi chamada a desempenhar novos papéis, com a modernização agropecuária, com a expansão de um complexo agroindustrial, com a consolidação e ampliação do papel atacadodistribuidor, e com a introdução de capitais extrarregionais, Uberlândia passou a comandar e a centralizar tais atividades e, coerentemente, ascendeu na hierarquia urbana regional e também nacional, pois é certo que os lugares, a cada nova divisão territorial do trabalho, são chamados a uma transformação.

O desenvolvimento de novas e mais complexas estruturas nos setores produtivos causou profundas modificações em Uberlândia, uma vez que ampliou a esfera demográfica, aumentou a complexidade dos sistemas técnicos, gerou a refuncionalização e criação de novas funções, transformou a estrutura de empregos, intensificou as trocas e os fluxos internamente à região, bem como aumentou as possibilidades de uma maior integração com o território nacional, pois proporcionou o surgimento de especializações e, consequentemente, o aparecimento de complementaridades. O desenvolvimento das atividades econômicas, juntamente com a aceleração da urbanização, trouxe, como resultado, uma diversificação do conteúdo urbano e uma redefinição dos papéis exercidos por Uberlândia, que passou a polarizar os demais centros da região e também do noroeste e parte da região central de Minas Gerais, do nordeste paulista e do sudeste, sul e sudoeste goiano, 
indicando a presença de importantes solidariedades horizontais, isto é, a manutenção de relações contíguas no seu espaço de polarização. Além disso, tal centro vem alcançando um lugar de destaque no cenário nacional, por meio das interações espaciais estabelecidas por suas especializações, indicando a existência de verticalidades, ou seja, o estabelecimento de interações em um espaço descontínuo e a possibilidade de relações diretas com outros centros de mesmo porte, com as metrópoles regionais, com a metrópole nacional e também com cidades mundiais.

Uberaba, ao contrário, apresentou desenvolvimento discreto, o que ocasionou perda de sua importância na região. No que tange ao aspecto econômico, revelou crescimento relativo, estando, ainda, fortemente atrelada ao campo, especificamente à pecuária, destacando-se ainda como a Capital do Zebu. Há que se ressaltar que se trata de uma pecuária altamente modernizada, pois conta com um pólo de biotecnologia animal, com empresas e laboratórios de inseminação artificial e transferência de embriões. No contexto urbano, as atividades são marcadas por indústrias voltadas para a agricultura, com a presença de um importante setor de insumos e bens de produção agrícola, assim como por atividades de comércio e de serviços, que atendem à população local e microrregional.

Assim, a posição geográfica de Uberaba e Uberlândia foi alterada no sentido da inversão hierárquica, que resultou do processo de re-diferenciação. Num primeiro momento, um conjunto de transformações sócioeconômicas e tecnológicas, verificado na segunda metade do século XIX, possibilitou uma organização espacial que privilegiou Uberaba, que se transformou em foco de aceleração do processo de modernização para uma vasta região do Brasil Central. Num segundo momento, outro conjunto de transformações, que se fez presente a partir de segunda metade do século $X X$, promoveu uma reversão na posição geográfica desses centros, conferindo a Uberlândia uma posição privilegiada em prejuízo da posição de Uberaba. Tais transformações, tanto na primeira fase como na segunda, são resultantes do entrecruzamento de determinações gestadas em diversas escalas, do geral ao particular, do particular ao geral, assim como pela emergência de contingências ocorridas na organização socioespacial da própria região.

Essas transformações, mediatizadas por uma evolução desigual, resultam dos processos de convergência e divergência entre os principais centros, porque não se trata de diferenciação pura e simples, e, sim, de rediferenciação, uma vez que a posição geográfica desses foi alterada no sentido da inversão de hierarquia, indicando a existência de fatores de estancamento e regressão para Uberaba e de ascensão para Uberlândia. Nesse sentido, a ascensão do segundo centro só pode ser entendida na relação direta com a regressão do primeiro. Trata-se, portanto, de um processo paralelo de esvaziamento e de preenchimento das funções de centro regional, responsável pela re-diferenciação e consequente reatualização da rede urbana regional. Desse modo, os processos de convergência e de divergência respondem por uma evolução urbana desigual, posto que, no intervalo entre um momento e outro, processos de convergência orientaram a evolução dos referidos centros para um ponto comum de confluência, com uma simultânea igualização da importância urbano-regional, caracterizada por uma breve homogeneidade. A partir desse ponto de confluência, tais centros, orientados por processos divergentes, foram re-diferenciados, tendo suas trajetórias de evolução urbana seguido por direções distintas, visto que Uberlândia manteve o sentido ascendente, enquanto Uberaba o descendente, evidenciando uma reversão dos processos de convergência para processos de divergência.

Vale enfatizar que a transição de um para outro significou a imposição de novas racionalidades e a redefinição dos atores, que, por sua vez, promoveram a recombinação dos elementos característicos às redes urbanas, reatualizando o seu padrão espacial. Num primeiro momento, observou-se o predomínio de uma racionalidade local, definida pela atividade pastoril, período em que se destacou a elite uberabense e uma espacialidade gestada a partir desse centro; em seguida, observou-se o 
Proposições para a análise da diferenciação espacial nos estudos sobre

sobre rede urbana: as noções de convêrgencia e divergência, pp. 34 - 58

momento dos embates entre racionalidades regionais, uma ainda associada à atividade pastoril e outra relacionada com as atividades mercantis, marcados pelos conflitos entre a elite tradicional de Uberaba e a elite emergente de Uberlândia, resultando numa espacialidade marcada pela relativa paridade e simetria funcional, bem como pelo revezamento dos comandos regionais; e, finalmente, observou-se o momento de diversificação das racionalidades, no qual passaram a atuar atores de escalas distintas, locais, nacionais e internacionais, expresso por uma espacialidade com múltiplos circuitos, orientada por competitividades e complementaridades, bem como por coerências e rupturas, cujos benefícios foram mais bem aproveitados por Uberlândia, que alargou sua importância tanto em escala regional, quanto em escala nacional ${ }^{13}$, uma vez que sua elite mostrouse muito mais apta a acolher os imperativos das subsequentes divisões territoriais do trabalho.

Desse modo, nota-se que as racionalidades das novas divisões territoriais do trabalho, e também os novos agentes que a elas se vincularam, impõem fases consecutivas de estruturação socioespacial parciais ou completas. Portanto, a natureza desses processos depende das demandas dos agentes e de suas respectivas escalas de atuação. A natureza convergente desse processo de evolução socioespacial foi implementada no contexto de ascensão de uma nova elite regional, que se contrapôs à tradicional elite, estabelecendo relações de competição em nível regional, que impuseram processos simultâneos de esvaziamento e de preenchimento. A natureza divergente, por sua vez, instalou-se quando da consolidação efetiva dessa elite emergente e do relativo declínio da elite tradicional, particularmente pela sua capacidade de adequação ante as mudanças impostas por novas divisões territoriais do trabalho. A postura exitosa da elite uberabense, formalmente organizada em bases tradicionais, acarretou como tendência contrária a ascensão da elite uberlandense, informalmente organizada e sem enraizamentos. De fato, a passagem de um espaço-tempo para outro, caracterizada por mudanças com descontinuidade, acontece quando uma nova elite torna-se apta para criar as condições de contornar a competição e de preservá-la sob seu controle.

A contradição, entretanto, não está nos legados histórico-geográficos em si, mas no fato de se revelarem por meio de práticas socioespaciais, que, de um lado, implicam a criação e a manutenção da organização existente, sugerindo continuidades fundamentadas em práticas com efeitos convergentes; e, de outro lado, a recriação e o rompimento com essa organização preexistente, indicando descontinuidades marcadas por práticas com efeitos divergentes, que produzem uma diversidade efetiva. Em realidade, o controle torna-se, essencialmente, o controle das diferenças espaciais e são os agentes e suas práticas espaciais que contribuem, decisivamente, para o recriar dessas diferenças. Em realidade, esses atores criam, atualizam e reatualizam a organização socioespacial, por meio de práticas que se traduzem pelo controle dos processos que conformam a organização do espaço, orientandoos ora num sentido convergente, ora num sentido divergente. Nesses sentidos, a diferenciação espacial é sempre um dado em constante construção, porque a situação convergente é transitória e aparente.

De fato, observou-se que a evolução urbana de Uberaba e de Uberlândia foi orientada por tendências contraditórias, o que determinou a re-diferenciação e a consequente mudança do padrão espacial desse segmento da rede urbana. Em suma, é uma situação de evolução espacial desigual, orientada por processos de convergência e de divergência, que privilegiam a diferenciação e não a uniformização, demonstrando a instabilidade e a descontinuidade dos eventos no espaço, cujo resultado é a diversidade espacial, posto que não existem mecanismos capazes de assegurar a unidade e a igualização, sendo a diversidade o resultado mais provável, visto que a assincronia e a não-linearidade estão na base dessa dinâmica, que se expressa pelas contradições inerentes ao movimento e à mudança. 


\section{Considerações finais}

A diferenciação entre os centros de uma dada rede, bem como entre as próprias redes urbanas, foi, primordialmente, analisada "...em termos de suas funções, dimensões básicas de variação dos sistemas urbanos, relações entre tamanho demográfico e desenvolvimento, hierarquia urbana, e relações entre cidade e região", cujos detalhamentos encontram-se em Corrêa (1988, p.108). Tais análises, apesar das pontencialidades maiores ou menores de uma ou de outra, não atentam para a totalidade dos processos associados à natureza da rede urbana, que está inexoravelmente relacionada com os processos de mudança social e suas espaçotemporalidades distintas. Neles, está a base para a explicação das diferenças entre os centros urbanos e para a diversidade de suas redes. Assim, a essência dessas análises não deve apenas permanecer situada na descrição dos aspectos da mudança, ao contrário, deve centrar-se nas racionalidades que deflagram o processo de transformação, assim como nos contextos espaciais e históricos, levando em conta a noção de rede urbana como dimensão socioespacial.

Em sendo a rede urbana uma dimensão socioespacial, crescentemente diferenciada e complexificada, esta passa a ser submetida a tensões numerosas e profundas que se impõem sobre sua estrutura e funcionamento, levando a mudanças, por vezes, lentas, orientando-se por uma continuidade especiosa; por vezes, rápidas, fundamentadas em princípios diferentes dos anteriores; e, não raro, brutais, rompendo com os padrões precedentes. Trata-se, respectivamente, de mudanças com continuidade e mudanças com descontinuidade, posto que a cada momento histórico e a cada contexto espacial, tem-se o embate entre tais processos, caracterizando a incessante renovação da sociedade e, por conseguinte, a recriação constante de diferencialidades espaciais.

Nessa perspectiva, as noções de convergência e divergência abrem possibilidades para o entendimento da natureza da rede urbana e dos seus complexos processos de formação, evolução e transformação. De fato, as transformações por que passam os segmentos da rede urbana não são iguais, visto que a recombinação dos mesmos elementos, que altera sua natureza, revelando diferenças espaciais antigas e novas, é comandada, primordialmente, por ações convergentes e divergentes, oriundas de processos internos e externos, o que aumenta sistematicamente a complexidade. A rede urbana, sofrendo reatualizações sucessivas, mantém características das combinações passadas e acumula características das novas combinações, e todas deixam suas marcas entremeadas na estrutura da rede vigente, cuja racionalidade está intrinsecamente condicionada pelas anteriores, especialmente pela inércia das formas espaciais pretéritas, sugerindo uma relação dialética do novo e do velho. Assim, como observa Corrêa (2000, p.125), "...uma rede urbana pode exibir características associadas aos diversos momentos da formação em que está inscrita, ou das diversas formações espaciais a que esteve associada".

Destarte, cumpre ressaltar que, na análise geográfica, é necessário abordar as redes urbanas como realidades complexas, que resultam de combinações múltiplas, determinadas pela fixidez espaço-temporal daqueles elementos que Ihe são pertinentes, cuja recombinação expressa o seu movimento de transformação. Os processos atuais de mudança social têm exercido um grande efeito sobre os centros urbanos e suas respectivas redes. De fato, a rede urbana passa por transformações que não necessariamente seguem um arquétipo único, pois apresentam variações consideráveis que dependem das características dos contextos espaciais e históricos, assim como das atitudes e práticas dos agentes econômicos, políticos e sociais. Portanto, convém salientar que a complexidade da estrutura socioespacial e a complexidade da rede urbana são correlatas. De fato, a rede urbana é expressão continuamente atualizada de uma estrutura social crescentemente diferenciada e complexa. Por essa razão, as noções de convergência e divergência são pertinentes, principalmente se combinadas às categorias tradicionalmente utilizadas nas análises espaciais e aos procedimentos que estão diretamente vinculados aos estudos sobre rede urbana, pois possuem poder explicativo suficiente para dar 
Proposições para a análise da diferenciação espacial nos estudos sobre

sobre rede urbana: as noções de convêrgencia e divergência, pp. 34 - 58

conta da complexidade das mudanças que envolvem as transformações dos seus padrões espaciais, especialmente no que diz respeito à diferenciação espacial, a exemplo dos processos entre Uberaba e Uberlândia, no segmento da rede urbana no Triângulo Mineiro, que resultaram em padrões consecutivos de de igualização e rediferenciação.

\section{Notas}

${ }^{1}$ Este artigo é uma versão já modificada dos capítulos 1 e 3 da Tese de Doutorado intitulada Convergências e divergências da urbanização em áreas de cerrado: a dinâmica urbano-regional de Uberaba e Uberlândia (MG), defendida em junho de 2007. Assim sendo, é importante agradecer, especialmente, ao Professor Doutor Roberto Lobato Corrêa, pela valiosa orientação.

${ }^{2}$ Corrêa (1988, p.117) salienta que o caráter de mutabilidade da rede urbana "...se traduz em uma periodização", pois cada momento de estabilidade e de mutabilidade da rede constitui-se em recortes espaço-temporais ou, como discrimina Sánchez (1991, p.49), em "..momentos históricoterritoriais".

${ }^{3}$ Os estudos sincrônicos são também bastante úteis, pois possibilitam o exame de situações socioespaciais concretas, num determinado momento, expressando suas singularidades. Dessa maneira, como sugere Corrêa (2000, p.126), pode-se falar em redes urbanas "...dos tipos solar, dendrítico, christalleriano, axial, circular e de múltiplos circuitos".

${ }^{4} \mathrm{~A}$ revolução dos hábitos de consumo atinge os pequenos centros e o campo. De acordo com Santos (1993, p.50), "...criam-se no mundo agrícola formas novas de consumo produtivo... com a modernização agrícola, o consumo produtivo tende a se expandir e a representar uma parcela importante das trocas entre os lugares da produção agrícola e as localidades urbanas".

${ }^{5}$ No Brasil, sobressaem as obras de Ribeiro (1970, 1979), dentre outras.

${ }^{6}$ Segundo Giddens (1991, p.14), tais teorias, embora não sejam teleologicamente inspiradas, posto que admitem a possibilidade de desvios nesse padrão, "...vêem a história humana como tendo uma direção global, governada por princípios dinâmicos gerais".

${ }^{7}$ Giddens (1991, p. 14) observa que "...existem indiscutivelmente descontinuidades em várias fases do desenvolvimento histórico".

${ }^{8}$ Giddens (1991, p.58) utiliza a expressão "...desencaixe dos sistemas sociais", como a resultante dos processos de "...separação ou distanciamento do tempo e do espaço", responsáveis pelo dinamismo da modernidade. Os mecanismos de desencaixe, segundo o autor, retiram "...a atividade social dos contextos localizados, reorganizando as relações sociais através de grandes distancias tempo-espaço". Giddens (1991, p.27) segue explicando que "...os locais são completamente penetrados e moldados em termos de influências sociais bem distantes deles. O que estrutura o local não é simplesmente o que está presente em cena; a 'forma visível' do local oculta as relações distanciadas que determinam sua natureza".

${ }^{9}$ Nessa discussão, Smith (1988, p.174) esclarece que "...a igualização das diferenças e o encolhimento do espaço aparecem juntos". Contudo, segundo o autor, "...a a-espacialidade aqui é o reverso da utopia".

${ }^{10}$ De acordo com Arrighi (1997, p.19), "...o capitalismo tende a gerar inovações que rompem qualquer ordem costumeira que tenha sido, ou esteja sendo, estabelecida em um momento dado".

${ }^{11}$ Silveira (1999, p.422) ressalta que "...o 'território' parece ser um personagem rebelde às máscaras". Santos (1993, p.118), nesse mesmo sentido, observa que "...os processos espaciais 
são condicionantes duráveis das ações inovadoras..." que "...dependem do quadro geográfico, que facilita ou restringe, autoriza ou proíbe a ação humana". Trata-se, na verdade, de uma espessura do contexto espacial, fazendo um paralelo com a expressão de Braudel acerca da espessura do momento histórico, como parafraseou Santos (1993).

${ }^{12}$ Mesmo a concepção de que uma sociedade em rede significaria uma sociedade indiferenciada é temerosa, pois, como afirma Bakis (1993, p.66), o próprio desenvolvimento múltiplo de redes "...não tem permitido a aparição de um espaço indiferenciado".

${ }^{13} \mathrm{Um}$ dos fatos mais importantes foi o aumento das escalas e do alcance das redes de poder e de acumulação que permitiram a Uberlândia reorganizar e controlar o segmento da rede urbana regional, bem como inserir-se de maneira diferenciada na rede urbana nacional.

\section{Bibliografia}

ARRIGHI, Giovanni. O longo século $X X$. Rio de Janeiro: Contraponto, 1996. 371p. ABRAMOVITZ, Moses. Catching up, forging ahead, and falling behind. The Journal of Economic History, Iowa, v. XLVI, n.2, p.385406, jun. 1986.

BAKIS, Henry. Les réseaux et leurs enjeux sociaux. Paris: Presses Universitaires de France, 1993.

BARRO, Robert J.; SALA-I-MARTIN, Xavier. Convergence. Journal of Political Economy, Chicago, v.100, n.1, p.223-251, apr.1992.

BESSA, Kelly C. F. O. Convergências e divergências da urbanização em áreas de cerrado: a dinâmica urbano-regional de Uberaba e Uberlândia (MG). 2007. 371f. Tese (Doutorado em Geografia) - Programa de Pós-Graduação em Geografia da Universidade Federal do Rio de Janeiro, Rio de Janeiro. 2007.

CASTELLS, M. A sociedade em rede. São Paulo: Paz e Terra, 1999. 617p. v. 1.

CLARK, David. Introdução à Geografia Urbana. 2 ed. Rio de Janeiro: Bertrand Brasil, 1991. $286 p$.

CORRÊA, Roberto L. Estudos sobre rede urbana. Rio de Janeiro: Bertrand Brasil. 2006. 330p.

A rede urbana: reflexões, hipóteses e questionamentos sobre uma temática à margem. Revista Cidades, Presidente Prudente, v.1, n.1, p.65-78, jan./jun.2004.
- A rede urbana brasileira e a sua dinâmica: algumas reflexões e questões. In: SPÓSITO, M. E. B. Urbanização e cidades: perspectivas geográficas. Presidente Prudente: [s.n.], 2001. p.359-367.

. Rede urbana e formação espacial - uma reflexão considerando o Brasil. Revista Território, Rio de Janeiro: Garamond, ano V, n.8, p.121-129, jan./jun.2000. - Globalização e reestruturação da rede urbana - uma nota sobre as pequenas cidades. Revista Território, Rio de Janeiro, n.6, p.43153, jan./jun.1999.

. Interações espaciais. In: CASTRO, Iná E. de; GOMES, Paulo Cesar da C.; CORRÊA, Roberto L. (Org.). Explorações geográficas: percursos no fim do século. Rio de Janeiro: Bertrand Brasil, 1997. p.279-318.

. A rede urbana. São Paulo: Ática, 1989.

$96 p$.

. O estudo da rede urbana: uma proposição metodológica. Revista Brasileira de Geografia, Rio de Janeiro, ano 50, n.2, p.107124, abr./jun.1988.

Os estudos de redes urbanas no Brasil. Revista Brasileira de Geografia, Rio de Janeiro: IBGE, ano 29, n.4, p.93-116, out./dez.1967.

DAVIDOVICH, Fani. Tendências da urbanização no Brasil, uma análise espacial. Revista 
Proposições para a análise da diferenciação espacial nos estudos sobre

sobre rede urbana: as noções de convêrgencia e divergência, pp. 34 - 58

Brasileira de Geografia, Rio de Janeiro, ano 51, n.1, p.73-88, jan./mar.1989.

Escalas de urbanização: uma perspectiva geográfica do sistema urbano brasileiro. Revista Brasileira de Geografia, Rio de Janeiro, ano 40, n.1, p.51-82, jan./ mar.1978.

DAVIDOVICH, Fani; LIMA, Olga Maria B. de. Análise de aglomerações urbanas no Brasil. Revista Brasileira de Geografia, Rio de Janeiro, ano 38, n.4, p.106-130, out./dez.1976.

Contribuição ao estudo de aglomerações urbanas no Brasil. Revista Brasileira de Geografia, Rio de Janeiro, ano 37, n.1, p.50-84, jan./mar.1975.

DEFFONTAINES, Pierre. Como se constituiu no Brasil e rede de cidades. Boletim Geográfico, Rio de Janeiro, ano II, n.14, p.141-148, abr.1944.

ELIAS, Norbert. O processo civilizador. Rio de Janeiro: Jorge Zahar, 1990. 271p.

FAISSOL, Esperidião. Urbanização e regionalização - relações com o desenvolvimento econômico. O sistema urbano brasileiro: uma análise e interpretação para fins de planejamento. Rio de Janeiro: IBGE, 1975. 247p.

O sistema urbano brasileiro: uma análise e interpretação para fins de planejamento. Revista Brasileira de Geografia, Rio de Janeiro, ano 35, n.4, out./dez.1973.

FERRARI, Onorina F. A organização espacial do Agreste e do Sertão de Alagoas: a redefinição dos centros urbanos. Rio de Janeiro: IBGE, 1988. 51p. (Cadernos de Geociências, n.1).

FREDRICH, Olga M. B. L.; DAVIDOVICH, Fany. A configuração espacial do sistema urbano brasileiro como expressão no território da divisão social do trabalho. Revista Brasileira de Geografia, Rio de Janeiro, ano 44, n.4, p.541590, out./dez.1982.
GEIGER, Pedro Pinchas. Evolução da rêde urbana brasileira. Rio de Janeiro: Instituto Nacional de Estudos Pedagógicos/Ministério da Educação e Cultura, 1963. 462p.

GERSCHENKRON, Alexander. Economic backwardness in historical perspective: a book of essays. Cambridge/London: Belknap Press, 1962. 456p. (ver Introdução [p.1-3] e Capítulo 1 - Economic bacrwardnees in historical perspective [p.5-30]).

GIDDENS, Anthony. Modernidade e identidade. Rio de Janeiro: Jorge Zahar, 2002. 233p.

As conseqüências da modernidade. São

Paulo: Editora da Unesp, 1991. 177p.

HARVEY, David. Espaços de esperança. São

Paulo: Edições Loyola, 2004. 382p.

. A justiça social e a cidade. São Paulo: Hucitec, 1980. 291p.

MARTIN, Ron; SUNLEY, Peter. Slow convergence? The New Endogenous Growth Theory and regional development. Economic Geography, Worcester, v.74, n.3, p.201-227, jul.1998. (Traduzido p/ o português:

Convergência lenta? A Nova Teoria do Crescimento Endógeno e o desenvolvimento regional. Cadernos IPPUR, Rio de Janeiro, ano XIV, n.1, p.15-50, 2000).

MONBEIG, Pierre. O estudo geográfico das cidades. Boletim Geográfico, Rio de Janeiro, ano 1, n.7, p.7-29, out.1943.

RIBEIRO, Darcy. O processo civilizatório: etapas da evolução sócio-cultural. 5ed. Petrópolis: Vozes, 1979. 257p. (Estudos de Antropologia da Civilização).

As Américas e a civilização: processo de formação e causas do desenvolvimento desigual dos povos americanos. Rio de Janeiro: 
Civilização Brasileira, 1970. (Estudos de Antropologia da Civilização II).

ROCHEFORT, Michel. Métodos de estudos de redes urbanas. Boletim Geográfico, Rio de Janeiro, ano 19, n.160, p.3-18, 1961.

SÁNCHEZ, Joan-Eugeni. Espacio, economía y sociedad. Madrid, Siglo Veintiuno, 1991. 338p. SANTOS, Milton. A natureza do espaço: técnica e tempo/razão e emoção. São Paulo: Hucitec, 1996. 308p.

. A urbanização brasileira. São Paulo:

Hucitec, 1993. 147p.

- O espaço dividido: os dois circuitos da economia urbana dos países subdesenvolvidos. Rio de Janeiro: Francisco Alves, 1979. 345p.

Crescimento nacional e nova rede urbana: o exemplo do Brasil. Revista Brasileira de Geografia, Rio de Janeiro, v.29, n.4, p.78-92, out./dez. 1967.

SILVEIRA, Maria L. Um país, uma região: fim de século e modernidades na Argentina. São Paulo: Fapesp/Laboplan-USP, 1999. 488p.

SMITH, Neil. Desenvolvimento desigual: natureza, capital e a produção de espaço. Rio de Janeiro: Bertrand Brasil, 1988. 250p. [Uneven development, 1984].

SOLOW, Robert. Contribution to the Theory of Economic Growth. Quarterly Journal of Ecomomics, Cambridge, v. LXX, n.1, p.65-94, feb.1956.

SZTOMPKA, Piotr. A sociologia da mudança social. Rio de Janeiro: Civilização Brasileira, 1998. 568p.

THRIFT, Nigel. Visando o âmago da região. In: GREGORY, Derek; MARTIN, Ron; SMITH, Graham. (Org.). Geografia humana: sociedade, espaço e ciência social. Rio de Janeiro: Jorge Zahar, 1996. p.215-247.

TOURAINE, Alain. Poderemos viver juntos? Iguais e diferentes. Petrópolis: Vozes, 1999. $387 p$.

. Igualdade e diversidade: o sujeito democrático. Bauru: Edusc, 1998. 109p. VELTZ, Pierre. Mundialización, ciudades y territorios: la economia de archipiélago. Barcelona: Editorial Ariel, 1999. 254p.

WALLERSTEIN, Immanuel. Capitalismo histórico e civilização capitalista. Rio de Janeiro:

Contraponto, 2001. 143p.

Trabalho enviado em março de 2010 Trabalho aceito em setembro de 2010 